\title{
Effects of Pulse Duration on Structure and Surface Characteristics of Micro-Arc Oxidation Coatings Formed on Aluminum Alloy
}

\author{
M.S. YILMAZ* AND O. ŞAHIN \\ Gebze Technical University, Department of Materials Science and Engineering, 41400 Gebze, Kocaeli, Turkey

\begin{abstract}
Micro arc oxidation (MAO) of aluminum alloy samples was studied using bipolar pulses with various pulse
\end{abstract} \\ durations under constant duty cycle. The processing times were chosen as 20,30 and 40 minutes. The X-ray \\ diffraction (XRD) technique, scanning electron microscope (SEM), surface roughness measurement $\left(R_{a}\right)$ and in- \\ dentation tests were employed to investigate the phase distribution, microstructure, surface properties and hardness \\ of the coatings, respectively. By increasing the pulse duration and processing time, coatings with different surface \\ roughness, thickness and hardness were fabricated.
}

DOI: 10.12693/APhysPolA.129.673

PACS/topics: 81.05.Bx, 81.15.-z, 81.16.Pr

\section{Introduction}

Aluminum and its alloys are increasingly preferred due to their physical and chemical properties that make them suitable for many industrial applications. Nevertheless the low wear resistance and hardness of this metal limit its usage [1]. Friction and wear damages have a huge effect on governmental budget. In order to decrease these costs: (i) coating technologies should improve surface properties or (ii) selection of materials should be done properly. Coating methods are usually preferred due to their advantages. Therefore MAO receives an increased attention as an oxidation technique for thick and hard ceramic coatings on aluminum and its alloys [2].

MAO is an electrochemical process, which is carried out in liquid electrolytes. It is particularly suitable for producing hard ceramic surface on lightweight metals such as magnesium, titanium and aluminum, which are important metallic materials for automotive, electronics and aerospace industries $[3,4]$. The process employs high anode and cathode voltages, which trigger micro discharges at the metal-electrolyte interfaces. This causes high temperature and pressure on the surface of samples. In addition, rapid cooling by the surrounding electrolyte affects coating morphology and phase composition [3,5]. MAO forms a hard and thick oxide coatings that have excellent wear resistance, corrosion resistance and thermal resistance $[3,6,7]$.

In present study, MAO coatings were formed on the pure aluminum samples. Bipolar pulse generators and alkaline silicate electrolyte were used. Different duration of pulses and processing times were investigated. Our main targets were to find out the effect of pulse duration and processing time on the coatings properties such as thickness, roughness and microstructure.

*corresponding author; e-mail: msyilmaz@gyte.edu.tr

\section{Materials and methods}

In this study, bipolar pulse generators were used. The system has two high frequency converters (HFC), which can operate separately for positive $(12.5 \mathrm{~kW})$ and negative $(12.5 \mathrm{~kW})$ polarity. The surface roughness measurement was performed using Mitutoyo SJ-400 profilometer. The coating thickness measurement was performed using Fisher-Dualscope MP40E-S, which uses ultrasonic method. Identification of the phases was performed using a Brukers D8 (40 kW, $40 \mathrm{~mA})$ X-ray diffractometer. X-ray diffraction (XRD) analyses were carried out using $\mathrm{Cu} \mathrm{K}_{\alpha}$ radiation. Diffraction angle was varied between $30^{\circ}-90^{\circ}$, with a step increment of $0.02^{\circ}$ and accumulation time of $1 \mathrm{~s}$. Microstructures of the coatings were investigated under Philips XL30 field emission scanning electron microscope (SEM). Cross-sectional hardness tests were carried out with Mitutoyo MicroWizhard micro-hardness tester under indentation load of $20 \mathrm{~g}$. For the monitoring of the voltage and of the pulse durations and amplitude, Tektronix-TDS 2024C digital storage oscilloscope was used.

The elemental analysis of the aluminum substrates is given in Table I.

TABLE I

Result of spectral analysis of substrate.

\begin{tabular}{c|c|c|c|c|c|c|c|c|c|c}
\hline \hline $\mathrm{Al}$ & $\mathrm{Si}$ & $\mathrm{Mg}$ & $\mathrm{Cu}$ & $\mathrm{Mn}$ & $\mathrm{Fe}$ & $\mathrm{Zn}$ & $\mathrm{Sn}$ & $\mathrm{Pb}$ & $\mathrm{V}$ & $\begin{array}{c}\mathrm{Cr}+\mathrm{B}+\mathrm{Cd} \\
+\mathrm{Na}+\mathrm{Ti} \\
+\mathrm{Ca}+\mathrm{Bi}\end{array}$ \\
\hline 98.6 & 0.47 & 0.46 & 0.03 & 0.02 & 0.25 & 0.01 & 0.06 & 0.04 & 0.01 & 0.02
\end{tabular}

The prepared samples had a surface area of $4 \mathrm{~cm}^{2}$. All substrates were mechanically ground with 200-1200 mesh emery papers and cleaned ultrasonically for $5 \mathrm{~min}$ in acetone.

The duty cycle is determined as

$$
D_{t}=\left[t_{\mathrm{on}} /\left(t_{\mathrm{on}}+t_{\mathrm{off}}\right)\right] \times 100,
$$


where $t_{\text {on }}$ is the "on" duration and $t_{\text {off }}$ is the "off" duration during a single cycle [8]. Process parameters are given in Table II. Pulse durations and the sample codes are given in Table III.

TABLE II

Parameters of micro arc oxidation process and their values.

\begin{tabular}{c|c}
\hline \hline Parameter & Value \\
\hline Anode voltage $\left(V_{\mathrm{a}}\right)[9]$ & $500 \mathrm{~V}$ \\
Cathode voltage $\left(V_{\mathrm{k}}\right)[9]$ & $200 \mathrm{~V}$ \\
Anode pulse duration $\left(t_{\mathrm{on}}\right)$ & $300,800,1000 \mu \mathrm{s}$ \\
Cathode pulse duration $\left(t_{\mathrm{on}}\right)$ & $200,600,800 \mu \mathrm{s}$ \\
Duty cycle & $8 \%$ \\
Coating time, minutes & $20,30,40$ \\
Electrolyte temperature [10] & $25 \pm 5{ }^{\circ} \mathrm{C}$ \\
Electrolyte composition $[3,11,12]$ & $\mathrm{KOH}(2 \mathrm{~g} / \mathrm{l}),_{\mathrm{Na}_{2} \mathrm{SiO}_{3} \cdot 5 \mathrm{H}_{2} \mathrm{O}(9.5 \mathrm{~g} / \mathrm{l})}$
\end{tabular}

TABLE III

Electrical parameters of micro arc oxidation processes.

\begin{tabular}{c|c|c|c|c|c|c|c|c|c}
\hline \hline $\begin{array}{c}\text { Cathode pulse } \\
\text { duration }[\mu \mathrm{s}]\end{array}$ & 200 & 200 & 200 & 600 & 600 & 600 & 800 & 800 & 800 \\
\hline $\begin{array}{c}\text { Anode pulse } \\
\text { duration }[\mu \mathrm{s}]\end{array}$ & 300 & 300 & 300 & 800 & 800 & 800 & 1000 & 1000 & 1000 \\
\hline $\begin{array}{c}\text { Coating time } \\
{[\mathrm{min}]}\end{array}$ & 20 & 30 & 40 & 20 & 30 & 40 & 20 & 30 & 40 \\
\hline Sample code & A1 & A2 & A3 & B1 & B2 & B3 & C1 & C2 & C3
\end{tabular}

\section{Results and discussion}

\subsection{Thickness and roughness}

Values of the coating thickness and surface roughness of the prepared samples are shown in Fig. 1. It is known that the increase of the processing time usually causes

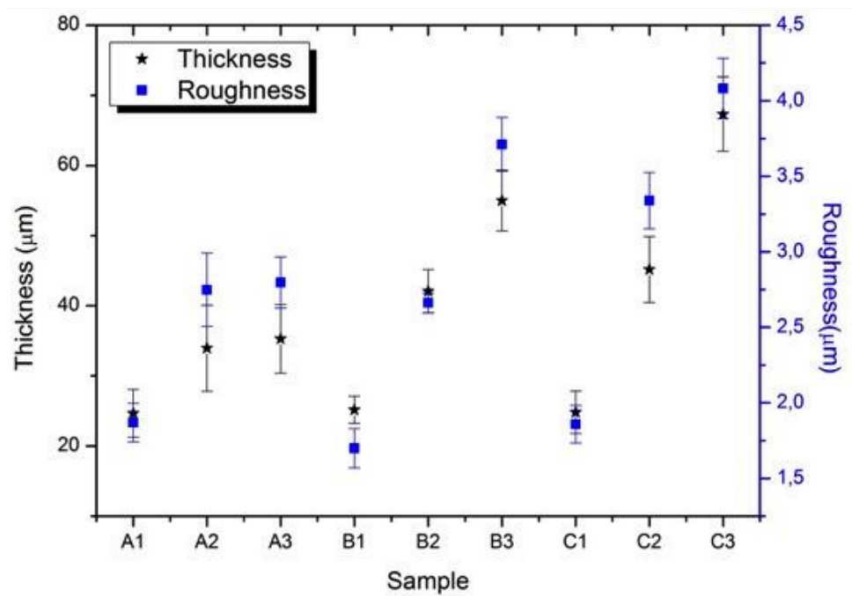

Fig. 1. Measured thickness and roughness values of the oxide coating of the prepared samples. Sample codes are explained in Table III. an increase in coating thickness [13]. Similarly, coating roughness increases with the increasing coating thickness [14]. In addition to increasing processing time, increasing pulse duration also causes an increase in coating thickness. The effect of increasing pulse duration on coating thickness was negligible for the processing time of 20 minutes, however it was significant for the processing time of 30 and 40 minutes. For example, the difference in thickness between samples $\mathrm{B} 2$ and $\mathrm{C} 2$ is around $3 \mu \mathrm{m}$, on the other hand thickness difference between samples B3 and C3 is around $11 \mu \mathrm{m}$. This effect is clearly seen in Fig. 1, the roughness increases with the increasing thickness of the coating.

Results show that the surface roughness of the coating usually increases with the increasing coating thickness, which in turn, increases with the processing time.

\subsection{XRD analysis}

$\mathrm{XRD}$ analyses were carried out to determine the phases present in the coatings and the results are given in Fig. 2. The $\mathrm{Al}$ and $\mathrm{Mg}_{2} \mathrm{Si}$ peaks, which belong to the substrate, were observed for almost all of the samples. The intensity of the $\mathrm{Mg}_{2} \mathrm{Si}$ peaks was decreasing with the increasing coating thickness and it was not observed in the sample C3. C3 had the maximum coating thickness among the prepared samples. $\gamma-\mathrm{Al}_{2} \mathrm{O}_{3}$ and $\alpha-\mathrm{Al}_{2} \mathrm{O}_{3}$ peaks were observed for all samples, with the exception of $\alpha-\mathrm{Al}_{2} \mathrm{O}_{3}$ peaks, which were not observed in samples of $\mathrm{A} 1$ and $\mathrm{A} 2$. The $\gamma-\mathrm{Al}_{2} \mathrm{O}_{3}$ phase is formed on the outer layer of coating, and causes the low hardness and rough surface of the oxide [15].

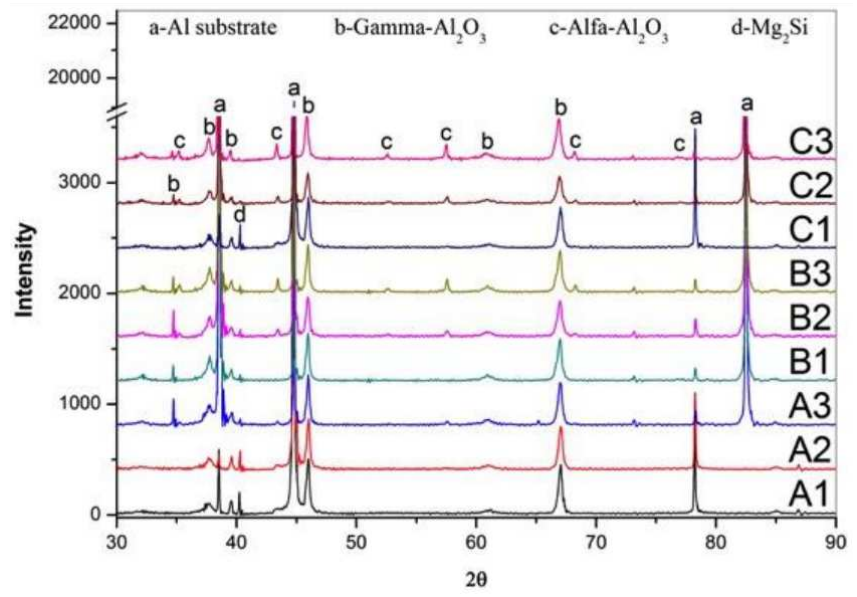

Fig. 2. XRD diagrams of the prepared samples.

The intensity of $\alpha-\mathrm{Al}_{2} \mathrm{O}_{3}$ for $\mathrm{B}$ and $\mathrm{C}$ series of the samples had increased with the increasing processing time. The most intense $\alpha-\mathrm{Al}_{2} \mathrm{O}_{3}$ peak was obtained for the sample $\mathrm{C} 3$, which has the longest pulse duration and processing time of the experiment.

\subsection{Hardness}

Hardness results are given in Fig. 3a and b. For the processing time of 20 minutes, the hardness profiles of coating layers are given in Fig. 3a. For these 
samples, coating layers consisted of $\gamma-\mathrm{Al}_{2} \mathrm{O}_{3}$. As a result, hardness profiles of A1, B1 and $\mathrm{C} 1$ were almost the same. The highest hardness value of around 1700 Vickers was at a depth of approximately $15 \mu \mathrm{m}$ from the coating surface. The thicknesses of coatings were approximately $25 \mu \mathrm{m}$. The hardness sharply decreased below the depth of $25 \mu \mathrm{m}$.
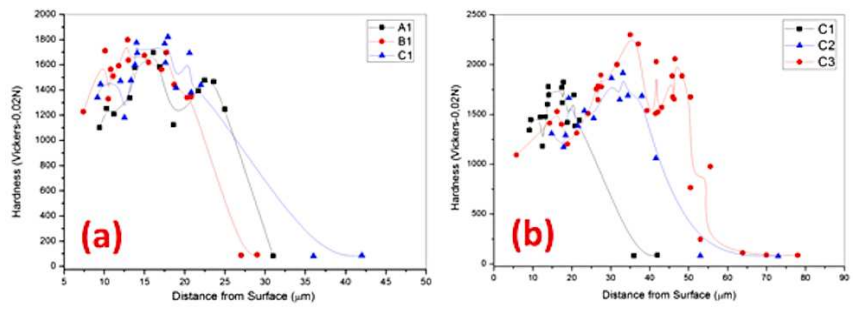

Fig. 3. Vickers hardness profiles of the coating layers.

The hardness profile of coating layers for samples C1, $\mathrm{C} 2$ and $\mathrm{C} 3$ are given in Fig. 3.b. These samples were formed using the same pulse duration and different processing times of 20 minutes (C1), 30 minutes (C2), 40 minutes (C3). The highest hardness values for samples C1, C2 and C3 were around 1700, 1900 and $2000 \mathrm{HV}$, respectively. These values were obtained at a depth of 15, 35 and 50 microns from the coating surface, respectively. For samples C1, C2 and C3 hardness has decreased sharply at a depth of 22, 40 and 52 micrometers respectively. That is, the coating-substrate interfaces were at a depth of around 22, 40 and $52 \mu \mathrm{m}$. For the samples $\mathrm{C} 2$ and $\mathrm{C} 3$, the depth of highest hardness was very close to the coating layer-substrate interface. Because a hard $\alpha-\mathrm{Al}_{2} \mathrm{O}_{3}$ phase was formed in the inner zone of coating that was very near to the interface $[9,16]$.

\section{4. $S E M$}

Cross sectional SEM results are given in Fig. 4. The samples were polish with colloidal silicate to deter-
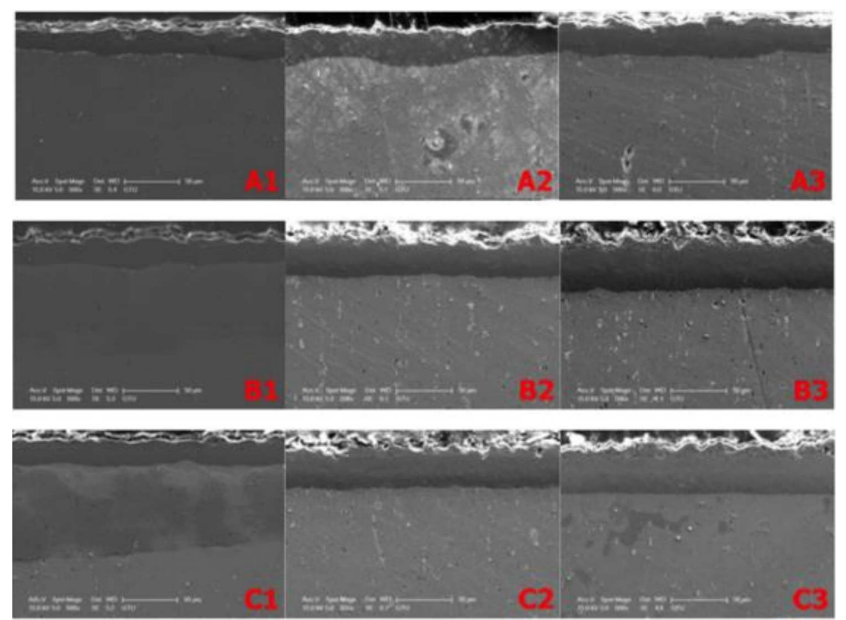

Fig. 4. The cross-sectional micrographs of the MAO coated samples.

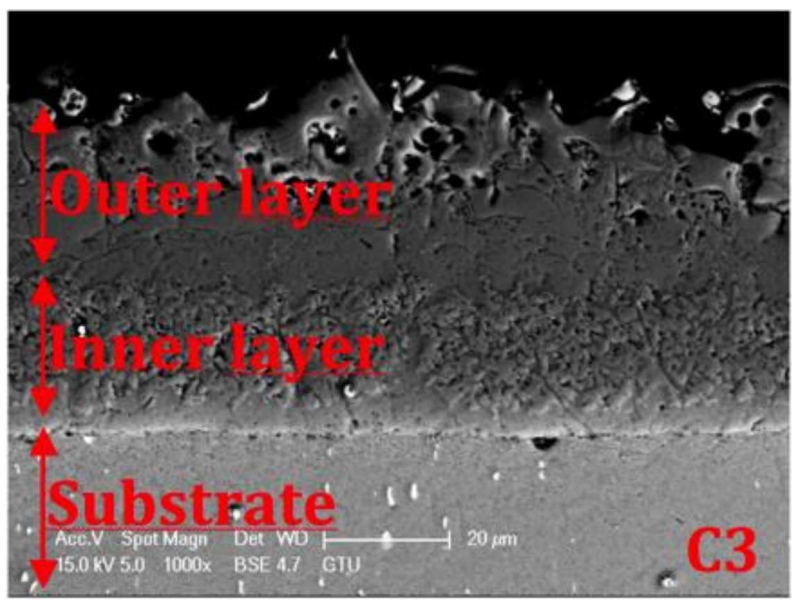

Fig. 5. The cross-sectional micrographs of sample C3.

mine the adhesion, thickness uniformity and microstructure of the coatings. It can be seen from Fig. 4 that the adhesion of coating to the substrate was excellent and all layers have smooth interfaces. Figure 4 demonstrates that the coating thickness increases with the increasing processing time.

In order to investigate the inner and outer layers, sample C3 was polished with alumina solution. The resulting SEM image is given in Fig. 5. The inner zone of coating, which is very close to the substrate, is $\alpha-\mathrm{Al}_{2} \mathrm{O}_{3}$. The outer zone of coating is mainly $\gamma-\mathrm{Al}_{2} \mathrm{O}_{3}$. The inner zone is dense and the outer zone is porous. Due to its higher intensity and harder phase, the hardness of inner zone is higher than that of outer zone of the coating [16].

\section{Conclusions}

The aim of the study was to investigate the improvement of the coating properties by changing pulse duration and processing time during micro arc oxidation of aluminum. The effect of pulse duration on coating thickness and hardness was determined experimentally. The increasing pulse duration and processing time generate thicker and harder coatings. The formation of $\alpha-\mathrm{Al}_{2} \mathrm{O}_{3}$ phase was promoted by increasing duration of pulses. Since the hardness of $\gamma-\mathrm{Al}_{2} \mathrm{O}_{3}$ phase is lower than that of $\alpha-\mathrm{Al}_{2} \mathrm{O}_{3}$ phase the hardness of outer zone of coatings was lower than that of the inner zones.

Obtaining an $\alpha-\mathrm{Al}_{2} \mathrm{O}_{3}$ layer close to the substrate is the main success of this study. It is demonstrated that pulse duration has a significant effect on coating microstructure and its properties such as thickness, roughness, composition and hardness.

\section{References}

[1] U. Malayoglu, K.C. Tekin, U. Malayoglu, S. Shrestha, Mat. Sci. Eng. A 528, 7451 (2011).

[2] G. Sundararajan, L.R. Krishna, Surf. Coat. Tech. 167, 269 (2003). 
[3] A.L. Yerokhin, X. Nie, A. Leyland, A. Matthews, S.J. Dowey, Surf. Coat. Tech. 122, 73 (1999).

[4] Y.F. Jiang, Y.Y. Zhang, Y.F. Bao, K. Yang, Wear 271, 1667 (2011).

[5] C.S. Dunleavy, I.O. Golosnoy, J.A. Curran, T.W. Clyne, Surf. Coat. Tech. 203, 3410 (2009).

[6] L.O. Snizhko, A.L. Yerokhin, N.L. Gurevina, V.A. Patalakha, A. Matthews, Thin Solid Films 516 460 (2007).

[7] A.L. Yerokhin, A. Shatrov, V. Samsonov, P. Shashkov, A. Pilkington, A. Leyland, A. Matthews, Surf. Coat. Tech. 199, 150 (2005)

[8] V. Dehnavi, B.L. Luan, D.W. Shoesmith, X.Y. Liu, S. Rohani, Surf. Coat. Tech. 226, 100 (2013).

[9] W.B. Xue, X.L. Wu, X.J. Li, H. Tian, J. Alloy. Compd. 425, 302 (2006).
[10] H. Kalkanci, S.C. Kurnaz, Surf. Coat. Tech. 203, 15 (2008)

[11] J. Martin, A. Melhem, I. Shchedrina, T. Duchanoy, A. Nomine, G. Henrion, T. Czerwiec, T. Belmonte, Surf. Coat. Tech. 221, 70 (2013).

[12] A.L. Yerokhin, A.A. Voevodin, V.V. Lyubimov, J. Zabinski, M. Donley, Surf. Coat. Tech. 110, 140 (1998).

[13] D.J. Shen, D.L. He, F.F. Liu, C.H. Guo, J.R. Cai, G.L. Li, H.J. Ma, Ultrasonics 54, 1065 (2014).

[14] M. Javidi, H. Fadaee, Appl. Surf. Sci. 286, 212 (2013).

[15] J.A. Curran, T.W. Clyne, Surf. Coat. Tech. 199, 168 (2005).

[16] D.T. Asquith, A.L. Yerokhin, J.R. Yates, A. Matthews, Thin Solid Films 515, 1187 (2006). 